\title{
CONTAMINAÇÃO DE HORTALIÇAS POR ENDOPARASITAS E SALMONELLA SPP. EM PRESIDENTE PRUDENTE, SÃO PAULO, BRAŠIL.
}

Vamilton Alvares Santarém ${ }^{1}$, Rogério Giuffrida ${ }^{1}$, Paula Andreia Fabris Chesine ${ }^{2}$

${ }^{1}$ Docente do Mestrado em Ciência Animal da UNOESTE. ${ }^{2}$ Mestre em Ciência Animal pela UNOESTE, Presidente Prudente - SP.

\section{RESUMO}

O objetivo do presente estudo foi o de avaliar a frequência de contaminação por endoparasitos e Salmonella spp. em hortaliças comercializadas em estabelecimentos do município de Presidente Prudente, São Paulo, Brasil. Amostras de duas variedades de alface e uma de agrião, salsa e cebolinha, além de pacotes de salsa e cebolinha foram obtidas de 96 dos 121 estabelecimentos comerciais do município. As folhas das hortaliças foram lavadas com Extran MA 02 a 0,5\% e o fluído resultante submetido às técnicas Baermann, Hoffmann e Faust, para recuperação de endoparasitos. A cultura bacteriana para Salmonella spp. foi executada pelas etapas de pré-enriquecimento, enriquecimento seletivo, plaqueamento diferencial e classificação bioquímica. Verificou-se que $33,06 \%$ das amostras apresentaram contaminação por estruturas parasitárias A maior contaminação estava presente no agrião $(69,2 \%)$ e salsa $(47,6 \%)$, enquanto a menor ocorreu em cebolinha $(20,7 \%)$ e alface $(20,0 \%)$. Os ovos do tipo tricostrongilídeos foram os mais frequentemente encontrados nas amostras. Cistos de Giardia duodenalis foram recuperados em 9,1\% das amostras. Em relação à presença Salmonella spp., apenas uma estirpe foi isolada em uma amostra de agrião $(1,04 \%)$. Conclui-se que existe a necessidade de uma campanha de educação em saúde para produtores, consumidores e comerciantes de hortaliças da região, baseada e nas técnicas de higienização, com a finalidade de reduzir os riscos de infecção por agentes infecciosos e parasitários ao se ingerir estes alimentos.

Palavras-chave: alimentos; bactérias; helmintos; protozoários; saúde pública.

CONTAMINATION OF VEGETABLES BY INTESTINAL PARASITES AND SALMONELLA SPP. IN PRESIDENTE PRUDENTE, SÃO PAULO STATE, BRAZIL.

\begin{abstract}
The aim of this study was to evaluate the frequency of contamination of vegetables by infective forms of helminths and protozoa commercialized in the municipality of Presidente Prudente, São Paulo, Brazil. Samples of two varieties of lettuce and one of watercress, parsley, chives, and packets of parsley and chives were collected from 96 out of 121 commercial establishments registered in the municipality. Samples were washed with Extran MA $020.5 \%$ and the resulting fluid subjected to techniques of Baermann, Hoffmann and Faust, in order to recovery parasite. Bacterial culture for Salmonella spp. was performed following the steps of pre-enrichment, selective enrichment, plating and differential biochemical classification. It was observed that $33.06 \%$ of the samples were contaminated by parasitic structures. The highest contaminations were present in watercress (69.2\%) and parsley (47.6\%), while the lowest occurred in chives (20.7\%) and lettuce (20.0\%). The eggs of trichostrongylidae type were most often found in the samples. Giardia duodenalis cysts were recovered in $9.1 \%$ of the samples. Regarding the presence of Salmonella spp., only one strain was isolated in a sample of watercress (1.04\%). It was conclude that there is a need for a health education campaign for farmers and vegetables merchants as well as for consumers, based on hygienic techniques, in order to reduce the risks of infection by infectious and parasitic agents during the ingestion of these foods.

Keywords: bacteria; food; helminths; protozoa; public health.
\end{abstract}




\section{INTRODUÇÃO}

As hortaliças frescas fazem parte da dieta de muitos indivíduos em razão de seus atributos nutricionais, preparo simples e baixo custo de produção. Apesar destes atrativos, o consumo destes alimentos crus ou minimamente processados está associado a surtos de gastrenterite causados por bactérias do gênero Salmonella spp. e parasitos como helmintos e protozoários (HANNING et al., 2009). Estima-se que a ingestão de vegetais folhosos crus é responsável por $17 \%$ dos surtos de doenças transmitidas por alimentos nos Estados Unidos (AYERS et al., 2009).

Bactérias e parasitos podem se instalar nas verduras em diversos pontos da cadeia de produção: plantio, colheita, processamento, distribuição e preparo final. As etapas mais críticas para o favorecimento da contaminação são o plantio, onde a adubação e irrigação são muitas vezes realizadas com água e esterco não tratados (NATVIG et al., 2002), e a manipulação pouco higiênica destes alimentos por indivíduos portadores assintomáticos de helmintoses e bactérias (DANCHAIVIJITR et al., 2005). Atualmente, o adubo natural constituído de esterco animal utilizado para o cultivo das hortaliças se popularizou com o advento da agricultura orgânica, representando risco adicional à transmissão de patógenos intestinais presentes nas fezes dos animais.

Salmonella spp. são bactérias responsáveis por aproximadamente metade dos casos registrados em surtos de gastrenterite decorrentes da ingestão de vegetais crus (SIVAPALASINGHAM et al. 2004). Os alimentos mais frequentemente evolvidos são a alface, o tomate, os melões e os brotos verdes frescos (HEATON; JONES, 2008). No Brasil, a bactéria foi identificada em amostras de diversas hortaliças como alface, escarola, rúcula e agrião comercializados em centros urbanos importantes do sudeste do país (GELLI et al., 1979; TAKAYANAGUI et al., 2001).

As parasitoses intestinais são doenças adaptadas às condições ambientais dos trópicos. De maneira similar á Salmonella spp., as formas infectantes dos helmintos e protozoários podem contaminar verduras, que na horta permanecem em contato com a matéria orgânica do solo e/ou adubo composto por esterco (BASUALDO et al., 2007). No Brasil, pesquisas constataram a presença de diversas formas infectantes de parasitos em verduras comercializadas em mercados de grandes centros urbanos (OLIVEIRA; GERMANO, 1992a,b; TAKAYANAGUI et al., 2001; SOARES; CANTOS, 2005).

A rastreabilidade das prováveis fontes de contaminação destes alimentos é um grande desafio para os sanitaristas dos países em desenvolvimento. $\mathrm{O}$ objetivo deste trabalho foi avaliar a freqüência de contaminação por formas infectantes de parasitos e de Salmonella spp., em hortaliças comercializadas no município de Presidente Prudente, São Paulo, Brasil.

\section{MATERIAL E MÉTODOS}

Durante o período de seis meses, foram coletadas 39 amostras constituídas por maços de alface da variedade crespa e 15 da variedade lisa (Lactuca sativa), 13 de agrião (Nasturtium officinale), 21 de salsinha (Petroselinum crispum), 4 de cebolinha (Allium fistulosum) e 29 de cheiro verde (salsa-cebolinha), em 41 dos 80 (51,25\%) estabelecimentos comerciais, conhecidos como sacolões, registrados no município de Presidente Prudente, São Paulo, Brasil.

Em cada ponto de venda foram coletadas de uma a duas amostras de cada tipo de hortaliça disponível, aleatoriamente. As amostras foram acondicionadas em sacos plásticos de primeiro 
uso, refrigeradas e imediatamente encaminhadas para os laboratórios de Medicina Veterinária Preventiva 1 e 2 da Universidade do Oeste Paulista, Presidente Prudente, São Paulo, Brasil

Antes da avaliação parasitológica, as folhas mortas de cada vegetal foram removidas e descartadas. As folhas restantes foram lavadas com 200 mL solução detergente de Extran MA 02 a 0,5\% com auxílio de borrifador e pincel. Ao término da etapa de lavagem, as folhas foram espremidas manualmente com auxílio de luvas de procedimento para remover o excesso de fluído.

Para a recuperação de ovos de helmintos e oocistos de protozoários utilizou-se a técnica de sedimentação (HOFFMAN, 1987). O fluído obtido do procedimento anterior foi filtrado com gaze e depositado em cálices de sedimentação. Cada cálice foi preenchido com água destilada para que o volume final atingisse $200,0 \mathrm{~mL}$, e permaneceram em repouso por 12 a 24 horas, em temperatura ambiente. Após este período, o sobrenadante foi desprezado e 50,0 $\mu \mathrm{L}$ do sedimento resultante foram aspirados e depositados em uma lâmina de vidro para avaliação microscópica das estruturas parasitárias, após serem corados com 0,03 mL de lugol.

Os cistos de Giardia duodenalis foram pesquisados pela técnica de centrifugo-flutuação, descrita por Faust et al., com pequenas modificações (HOFFMANN, 1987). De cada cálice de sedimentação preparado na etapa anterior, retirou-se $1,0 \mathrm{~mL}$ do sedimento para transferência em tubos graduados de centrífuga contendo solução de sulfato de zinco (densidade $1,180 \mathrm{~g} / \mathrm{cm}^{3}$ ). Os tubos foram centrifugado a 2500 rpm por cinco minutos e, após repouso vertical de cinco minutos, retirou-se com pipeta $40,0 \mu \mathrm{L}$ de sobrenadante para avaliação em microscopia ótica.

Das 121 verduras coletadas somente 96 apresentavam volume de material suficiente para avaliação microbiológica objetivando-se o isolamento de Salmonella spp, utilizando-se o pré-enriquecimento, o enriquecimento seletivo e o plaqueamento diferencial (SILVA et al., 2001). Utilizou-se, como inoculo inicial, uma mistura de cada hortaliça coletada do sedimento da lavagem para o exame parasitológico, perfazendo um total de 25,0 mL. O inoculo foi semeado em 225,0 mL de caldo lactosado, para o pré-enriquecimento das amostras. Os caldos semeados foram incubados em estufa a $35^{\circ} \mathrm{C}$ por 18 a 24 horas. Procedeu-se a seguir, o enriquecimento seletivo, em duplicata, inoculando-se $1,0 \mathrm{~mL}$ do caldo lactosado em 10,0 mL de caldo tetrationato de sódio e caldo Rappaport-Vassiliadis modificado. Após incubação, o material foi submetido, em triplicata, ao plaqueamento diferencial em ágar Salmonella-Shihgella, ágar entérico de Hektoin e ágar Xilose Lisina Deoxicolato (XLD), sendo incubadas a $35^{\circ} \mathrm{C}$ por 24 horas. As colônias com aspecto compatível com o gênero Salmonella foram identificadas por comportamento bioquímico nos seguintes meios: ágar trípliceferro-açucar, meio motilidade-lisina-indol, ágar citrato de Simmons, ágar fenilalanina e caldo uréia. As linhagens com identificação positiva nos testes bioquímicos foram submetidas ao sorodiagnóstico com anti-soro somático polivalente anti-Salmonella (Probac ${ }^{\circledR}$ ).

Para comparar as frequências de contaminação entre as diferentes hortaliças pesquisadas empregou-se 0 teste de quiquadrado ou teste exato de Fisher (MAROCO, 2007), adotando-se nível de significância de 5\%.

\section{RESULTADOS}

$\mathrm{Na}$ tabela 1 são apresentados os resultados das avaliações parasitológicas. Das 121 amostras avaliadas, observou-se contaminação por algum tipo de endoparasitos em 40 delas $(33,06 \%)$. 
As frequências de contaminação da alface crespa e do agrião foram significativamente superiores a da cebolinha, enquanto a contaminação da salsinha $(47,6 \%)$ foi superior à dos maços de salsa-cebolinha $(20,7 \%)$.

Tabela 1. Comparação entre a frequência de contaminação por estruturas parasitárias em hortaliças comercializadas no município de Presidente Prudente, São Paulo, Brasil, 2010.

\begin{tabular}{lcccc}
\hline \multirow{2}{*}{ Hortaliça/Frequência (\%) } & \multicolumn{2}{c}{ Positivo } & \multicolumn{2}{c}{ Negativo } \\
\cline { 2 - 5 } Agrião & $\mathrm{n} / \mathrm{N}$ & $\%$ & $\mathrm{n} / \mathrm{N}$ & $\%$ \\
Alface crespa & $9 / 13$ & $69,2^{\mathrm{a}}$ & $4 / 13$ & 40,8 \\
Alface lisa & $11 / 39$ & $28,2^{\mathrm{a}}$ & $28 / 39$ & 71,8 \\
Cebolinha & $3 / 15$ & $20,0^{\text {ab }}$ & $12 / 15$ & 80,0 \\
Salsinha & $1 / 4$ & $25,0^{\mathrm{b}}$ & $3 / 4$ & 75,0 \\
Salsinha/Cebolinha & $10 / 21$ & $47,6^{\text {ab }}$ & $11 / 21$ & 52,4 \\
\hline
\end{tabular}

- Número seguido de letras sobrescritas diferentes em uma mesma coluna, representa diferença significativa entre as frequências $(p<0,05)$.

A maior frequência de estruturas parasitárias presentes nas hortaliças deveu-se à contaminação por ovos de tricostrongilídeos e de Ascaris spp. (Tabela 2).

Tabela 2. Frequência (\%) de estruturas parasitárias de helmintos e protozoários observados em hortaliças comercializadas em estabelecimentos de Presidente Prudente, São Paulo, Brasil, 2010.

\begin{tabular}{|c|c|c|c|c|c|c|c|}
\hline $\begin{array}{c}\text { Hortaliça/ } \\
\text { Estrutura } \\
\text { parasitária }\end{array}$ & $\begin{array}{c}\text { Agr } \\
(n=13)\end{array}$ & $\begin{array}{c}A C \\
(n=39)\end{array}$ & $\begin{array}{c}A L \\
(n=15)\end{array}$ & $\begin{array}{c}\text { Ceb } \\
(n=4)\end{array}$ & $\begin{array}{c}\text { Sal } \\
(n=21)\end{array}$ & $\begin{array}{c}\text { Sal/Ceb } \\
(n=29)\end{array}$ & $\begin{array}{c}\text { Total } \\
(n=121)\end{array}$ \\
\hline \multicolumn{8}{|l|}{ Ovos } \\
\hline Ancilostomídeo & 0,0 & 0,0 & 6,7 & 0,0 & 4,8 & 3,4 & 2,5 \\
\hline Ascaris & 38,5 & 2,6 & 6,7 & 0,0 & 9,5 & 0,0 & 7,4 \\
\hline Entamoeba & 7,7 & 5,1 & 0,0 & 0,0 & 9,5 & 0,0 & 4,1 \\
\hline Enterobius & 7,7 & 0,0 & 0,0 & 0,0 & 0,0 & 0,0 & 0,8 \\
\hline Hymenolepis & 0,0 & 0,0 & 0,0 & 0,0 & 4,5 & 3,4 & 1,7 \\
\hline Strongyloides & 15,4 & 2,6 & 6,7 & 0,0 & 0,0 & 3,4 & 4,1 \\
\hline Tricostrongilídeo & 53,8 & 7,7 & 20,0 & 25,0 & 19,0 & 13,8 & 18,2 \\
\hline Trichuris & 0,0 & 5,1 & 6,7 & 0,0 & 0,0 & 0,0 & 2,5 \\
\hline $\begin{array}{c}\text { Tricocephalus } \\
\text { Cistos }\end{array}$ & 0,0 & 7,7 & 0,0 & 0,0 & 0,0 & 0,0 & 2,5 \\
\hline $\begin{array}{c}\text { Giardia } \\
\text { Oocistos }\end{array}$ & 15,4 & 12,8 & 0,0 & 0,0 & 19,0 & 0,0 & 9,1 \\
\hline Tipo isosporóide & 7,7 & 10,3 & 20,0 & 0,0 & 0,0 & 0,0 & 6,6 \\
\hline
\end{tabular}

No agrião, foram observadas larvas de Trichostrongylus spp. em duas amostras, sendo que em uma delas também observou-se a presença de larvas de Ciatostomíneo. Em outra amostra foram recuperadas larvas de Oesophagostomum spp.

Em relação a Salmonella spp., houve isolamento em apenas uma amostra de agrião $(1,04 \%)$.

\section{DISCUSSÃO}

A frequência de contaminação das hortaliças por enteroparasitos neste estudo foi superior aos valores encontrados por outros pesquisadores em cidades brasileiras como o Rio de Janeiro (SILVA et al., 1995) e Maringá (GUILHERME et al., 1999). O agrião foi a hortaliça com maior percentual de enteroparasitos, fato observado em outras 
pesquisas realizadas na região metropolitana de São Paulo (66\%) (OLIVEIRA; GERMANO, 1992a,b) e Florianópolis (70,4\%) (SOARES; CANTOS, 2005), mas inferior ao encontrado em Maringá (100\%) (GUILHERME et al., 1999). No presente estudo, o agrião foi a única hortaliça com isolamento positivo para Salmonella spp.

Aparentemente, o agrião apresenta maior facilidade por contaminar-se com patógenos intestinais em relação a outros vegetais pesquisados, além de ser totalmente cultivada em água, tem estrutura composta por folhas múltiplas e separadas que facilitam a fixação de estruturas parasitárias e resíduos orgânicos fecais (GELLI et al., 1979). Vale ressaltar que a água sem tratamento, proveniente de açudes, barragens e de outros recursos hídricos constitui uma fonte de contaminação importante para hortaliças, tanto na cadeia produtiva e comercial, bem como no processo de higienização das mesmas pelos consumidores (SOARES; CANTOS, 2005).

A contaminação da cebolinha foi a mais baixa entre as hortaliças. No entanto, quando se avaliou o conjunto salsa-cebolinha, observou-se contaminação similar à avaliada para a salsinha isoladamente, havendo a possibilidade de contaminação cruzada entre as duas verduras durante seu transporte e/ou armazenamento conjunto.

Os tricostrongilídeos foram os helmintos mais freqüentemente observados, diferentemente dos padrões observados por outros pesquisadores (OLIVEIRA; GERMANO, 1992b) que detectaram percentuais mais elevados de ovos e larvas de acilostomídeos e Ascaris spp.

Alguns parasitos importantes para saúde pública não foram observados nas amostras pesquisadas, como é o caso da Fasciola hepatica, trematódeo que pode ser veiculado pela ingestão de metacercárias em agrião da água ou água contaminada. Este agente vem se expandindo de forma acelerada nos últimos anos e sua presença já foi registrada em zonas rurais da região do Oeste Paulista (TOSTES et al., 2004). Sua ausência nas hortaliças pesquisadas reitera a necessidade de estudos sobre as vias de transmissão, para elucidação das características epidemiológicas na região.

Ao contrário de pesquisas realizadas em outros centros urbanos (OLIVEIRA; GERMANO, 1992b; SILVA et al., 1995), não foram identificados ovos pertencentes ao gênero Taenia. Estudos parasitológicos realizados na região de Presidente Prudente comprovaram a baixa prevalência de teníase em populações carentes da região (TROIANI et al., 2009).

Trabalhos têm destacado a presença nas verduras de estruturas parasitárias como oocistos de coccídeos e ovos com morfologia semelhante às espécies que infectam animais (GUILHERME et al., 1999). No presente estudo, observou-se a presença de elementos que infectam tanto humanos quanto animais, mas cujas estruturas morfológicas são idênticas, dificultando sua identificação, como oocistos e cistos de protozoários, Strongyloides, Trichuris e tricostrongilídeos.

A recuperação de larvas de Oesophagostomum spp. e de ciatostomíneos, gêneros que parasitam ruminantes e eqüinos respectivamente, sugere que os agricultores que fornecem as hortaliças utilizam adubo orgânico animal composto por fezes frescas e sem tratamento prévio.

Outras estruturas observadas nas hortaliças apresentam características de parasitos que podem acometer o homem, como ovos de Ascaris spp., Entamoeba spp. e Hymenolepis nana, o que indica a contaminação das hortas por dejetos humanos ou a manipulação dos vegetais por indivíduos portadores. Guilherme et al. (1999) observaram a presença de parasitos em depósito ungueal de feirantes de Maringá, Paraná, o que 
pode refletir na contaminação das hortaliças comercializadas.

A baixa freqüência de hortaliças contaminadas por Salmonella spp. foi inferior ao constatado por em Ribeirão Preto (TAKAYANAGUI et al., 2001) e superior ao observado na região metropolitana de São Paulo (GELLI et al., 1979). A maior parte das hortaliças comercializadas no município atendeu as normas sanitárias recomendadas pela resolução número 12 da Agência Nacional de Vigilância Sanitária (BRASIL, 2001), que estabelece ausência de Salmonella spp. em $25 \mathrm{~g}$ de alimento. Apesar disso, a presença deste microrganismo em uma amostra de agrião sugere a possibilidade de ocorrência de surtos de salmonelose de origem alimentar na população exposta e a possibilidade contaminação das hortas por dejetos humanos e de animais.

A frequência de hortaliças com presença de Salmonella spp. foi inferior àquela observada para enteroparasitos, apesar de ambos contaminarem as verduras a partir de fontes comuns, possivelmente por que a bactéria é menos resistentes às adversidades ambientais do que os parasitas observados.

A presença de patógenos intestinais nas hortaliças comercializadas no município de Presidente Prudente é reflexo das condições em que são cultivadas e manipuladas, geralmente em zonas periféricas da cidade, com saneamento básico precário e proximidade às propriedades rurais destinadas à criação de animais de produção (SIMÕES et al., 2001). O problema pode ser agravado pela presença de remansos de água poluídos, pela descarga de dejetos humanos e/ou de animais (SOARES; CANTOS, 2005).

Considerando o risco potencial de transmissão aos consumidores, sugere-se 0 fortalecimento das ações de fiscalização sanitária nas hortas e no comércio varejista da região, abrangendo inclusive a saúde dos manipuladores de alimentos e ações de orientação para educação sanitária da população.

\section{AGRADECIMENTOS}

Os autores agradecem à Universidade do Oeste Paulista pelo apoio financeiro e à Vigilância Sanitária do Município de Presidente Prudente pelas coletas de amostras de hortaliças.

\section{REFERÊNCIAS}

AYERS, L. T.; WILLIAMS, I. T.; GRAY, S.; GRIFFIN, P. M. CDC. Centers for Disease Control and Prevention. Surveillance for foodborne disease outbreaks - United States, 2006. MMWR. Morbidity and Mortality Weekly Report, Atlanta, v. 58, n. 22, p. 609-615, 2009.

BASUALDO, J. A.; CÓRDOBA, M. A.; DE LUCA, M. M.; CIARMELA, M. L.; PEZZANI, B. C.; GRENOVERO, M. S.; MINVIELLE, M. C. Intestinal parasitoses and environmental factors in a rural population of Argentina, 2002-2003.

\section{Revista do Instituto de Medicina Tropical de}

São Paulo, São Paulo, v. 49, n. 4, p. 251-55, 2007. http://dx.doi:10.1590/S0036-

46652007000400011

BRASIL. Ministério da Saúde. Agência Nacional de Vigilância Sanitária (ANVISA). Resolução número 12 de 02 de janeiro de 2001. 2001. Disponível em: $<$ http://www.anvisa.gov.br/legis/resol/12_01rdc.ht $\mathrm{m}>$. Accesso em 02 de agosto de 2009.

DANCHAIVIJITR, S.; RONGRUNGRUANG, Y.; KACHINTORN, U.; TECHASATHIT. V.; PAKAWORAVUTHI, S.; KACHINTORN, K. Prevalence and effectiveness of an education program on intestinal pathogens in food handlers. Journal of the Medical Association of Thailand, Bankok, v. 88, sup. 10, p. 31-35, 2005. 
GELLI, D. S.; TACHIBANA, T.; OLIVEIRA, I. R.; ZAMBONI, C. Q.; PACHECO, J. A.; SPITERI, N. Condições higiênico-sanitárias de hortaliças comercializadas na cidade de São Paulo, SP, Brasil. Revista do Instituto Adolfo Lutz, São Paulo, v. 39, n. 1, p. 37-43, 1979.

GUILHERME, A. L.; ARAÚJO, S. M.;

FALAVIGNA, D. L.; PUPULIM, A. R.; DIAS, M. L.; OLIVEIRA, H. S.; MAROCO, E.; FUKUSHIGUE, Y. Prevalência de enteroparasitas em horticultores e hortaliças da Feira do Produtor de Maringá, Paraná. Revista da Sociedade Brasileira de Medicina Tropical, Uberlândia, v. 32, n. 4, p. 405-411, 1999.

HANNING, I. B.; NUTT, J. D.; RICKE, S. C. Salmonellosis outbreaks in the United States due to fresh produce: sources and potential intervention measures. Foodborne Pathogens and Disease, New York, v. 6, n. 6, p. 635-648, 2009. http://dx.doi:10.1089/fpd.2008.0232

HEATON, J. C.; JONES, K. Microbial contamination of fruit and vegetables and the behaviour of enteropathogens in the phyllosphere: a review. Journal of Applied Microbiology, New York, v.104, n. 3, p. 613-626, 2008. http://dx.doi:10.1111/j.1365-2672.2007.03587.x

HOFFMANN, R. P. Parasitologia Veterinária. Porto Alegre: Sulina, 1987.

\section{MAROCO, J. Análise estatística com a}

utilização do SPSS. Lisboa: Silabo, 2007.

NATVIG, E. E.; INGHAM, S. C.; INGHAM, B. H.; COOPERBAND, L. R.; ROPER, T. R. Salmonella enterica serovar Typhimurium and Escherichia coli contamination of root and leaf vegetables grown in soils with incorporated bovine manure.

Applied and Environmental Microbiology, Washington, v. 68, n. 6, p. 2737-2744, 2002. http://dx.doi:10.1128/AEM.68.6.2737-2744.2002

OLIVEIRA, C. A. F.; GERMANO, P. M. L. Estudo da ocorrência de enteroparasitas em hortaliças comercializadas na região metropolitana de São Paulo - SP, Brasil: II - Pesquisa de helmintos.

Revista de Saúde Pública, São Paulo, v. 26, n. 4, p. 283-289, 1992a.

OLIVEIRA, C. A. F.; GERMANO, P. M. L. Estudo da ocorrência de enteroparasitas em hortaliças comercializadas na região metropolitana de São Paulo - SP, Brasil: II - Pesquisa de protozoários intestinais. Revista de Saúde Pública, São Paulo, v. 26, n. 5, p. 332-335, 1992b.

SILVA, J. P.; MARZOCHI, M. C.; CAMILLOCOURA, L.; MESSIAS, A. A.; MARQUES S. Estudo da contaminação por enteroparasitas em hortaliças comercializadas nos supermercados da cidade do Rio de Janeiro. Revista da Sociedade Brasileira de Medicina Tropical, Uberlândia, v. 28, n. 3, p. 237-241, 1995.

SILVA, N.; JUNQUEIRA, V. C. A.; SILVEIRA, N. F. A. Manual de métodos de análise microbiológica de alimentos. 2. ed. São Paulo: Livraria Varela, 2001.

SIMÕES, M.; PISANI, B.; MARQUES, E. G. L.; MARIA PRANDI, A. G.; MARTINI, M. H.; CHIARINI, P. F. T.; ANTUNES, J. L. F.; NOGUEIRA, A. P. Hygienic-sanitary conditions of vegetables and irrigation water from kitchen gardens in the municipality of Campinas, SP. Brazilian Journal of Microbiology, São Paulo, v. 32, n. 4, p. 331-333, 2001.

http://dx.doi.org/10.1590/S151783822001000400015

SIVAPALASINGAM, S.; FRIEDMAN, C. R.; COHEN, L.; TAUXE, R. V. Fresh produce: a growing cause of outbreaks of foodborne illness in the United States, 1973 through 1997. Journal of Food Protection, Des Moines, v. 67, n. 10, p. 2342-2353, 2004.

SOARES, B.; CANTOS, G. A. Parasitological quality and hygienic-sanitary conditions of vegetables sold in the city of Florianópolis, Santa 
Catarina, Brazil. Revista Brasileira de

Epidemiologia, São Paulo, v. 8, n. 4, p. 377-384,

2005. http://dx.doi.org/10.1590/S1415-

$790 \times 2005000400006$

TAKAYANAGUI, O. M.; OLIVEIRA, C. D.;

BERGAMINI, A. M. M.; CAPUANO, D. M.;

OKINO, M. H. T.; FEBRÔNIO, L. H. P.; CASTRO

E SILVA, A. A. M. C.; OLIVEIRA, M. A.; RIBEIRO,

E. G. A.; TAKAYANAGUI, A. M. M. Fiscalização

de verduras comercializadas no município de

Ribeirão Preto, SP. Revista da Sociedade

Brasileira de Medicina Tropical, São Paulo, v.

34, n. 1, p. 337-341, 2001.

http://dx.doi.org/10.1590/S0037-

86822001000100006

TOSTES, R. A.; SANTARÉM, V. A.; ALBERTI, H.; SANCHES, O. C. Casos autóctones de Fasciola hepatica na região de Presidente Prudente, São Paulo, Brasil. Ciência Rural, Santa Maria, v. 34, n. 3, p. 961-962, 2004.

http://dx.doi.org/10.1590/S0103-

84782004000300051

TROIANI, C.; NASCIMENTO, M. U.; KAYAHARA, M.; PRESTES-CARNEIRO, L. E. Prevalência de enteroparasitas em indivíduos de um município do pontal do Paranapanema (Teodoro SampaioSP). Newslab, São Paulo, n. 92, p. 138-144, 2009. 